Article

\title{
An Ensemble Framework to Investigate Wind Energy Sustainability Considering Climate Change Impacts
}

\author{
Shengjin Wang ${ }^{1}$, Hongru Yang ${ }^{1}$, Quoc Bao Pham ${ }^{2}$, Dao Nguyen Khoi ${ }^{3}$ and \\ Pham Thi Thao Nhi ${ }^{4, *}$ \\ 1 Northeast Asia Research Institute, Jilin University, Changchun 130012, China; \\ SJin_Wang@outlook.com (S.W.); Hongru_Y@outlook.com (H.Y.) \\ 2 Department of Hydraulic and Ocean Engineering, National Cheng-Kung University, Tainan 701, Taiwan; \\ pbquoc92@gmail.com \\ 3 Faculty of Environment, University of Science, Vietnam National University Ho Chi Minh City, Ho Chi Minh \\ City 700000, Vietnam; dnkhoi@hcmus.edu.vn \\ 4 Institute of Research and Development, Duy Tan University, Danang 550000, Vietnam \\ * Correspondence: Phamtthaonhi2@duytan.edu.vn
}

Received: 3 December 2019; Accepted: 2 January 2020; Published: 24 January 2020

check for updates

\begin{abstract}
Wind power is a key element for future renewable energy resources and plays a vital role in sustainable development. Global warming and future climate conditions are going to impact many atmospheric, oceanic, and earth systems. In this study, impacts of climate change on wind power resources under future climatic conditions are evaluated for the Persian Gulf to explore the sustainability of this kind of energy for present and future developments. To that end, three regional climate models obtained from coordinated regional downscaling experiment (CRODEX), including daily simulations of near-surface wind speeds for a 20 -year period in the present and future, were considered. Prior to computing the wind power at turbine hub-height, historical simulations of CORDEX were evaluated versus ERA-Interim wind outputs to determine the accuracy of the regional climate models. An attempt was made to build an ensemble model from available models by assigning weights to the models based on their merits. Subsequently, the wind power at the turbine hub-height was computed for historical and future periods to detect the impacts of climate change. Some points with a relatively high energy potential were selected as energy hotspots for further investigations. The results revealed that the mean annual wind power over the study area changed remarkably, which is of great importance for sustainable developments. Moreover, the results of the directional investigations showed roughly the same directional distribution for the future period as the past.
\end{abstract}

Keywords: wind power; sustainability; ensemble; climate change; energy hotspots

\section{Introduction}

Global warming - as a result of the increasing greenhouse gas emissions - is considered to be a worldwide concern and requires serious action to be taken and remedies to be found to control and adapt to its impacts on weather patterns, health, and the environment. In this regard, renewable energies as an appropriate alternative for fossil fuels (as the largest source of greenhouse gas emissions from human activities) have attracted a great deal of attention to meet the demand for energy supplies. Wind energy is amongst the most important elements of renewable energy resources due to its widespread distribution throughout the world and its potential to provide energy. However, the investigation of the impacts of climate change on future wind power resources is a key step toward sustainable development. Global circulation models (GCMs) run by different institutes provide simulations of atmospheric and oceanic parameters for present and future scenarios with different 
spatial and temporal resolutions. These models have been developed by employing different numerical schemes and different assumptions. Since these models have been run globally and originally have coarse resolution, the regionalization of their outputs for local studies and to achieve more accurate results is of great interest. Moreover, previous studies considering different GCMs have demonstrated that the impacts of climate change on different variables have a strong spatial variability distribution, in which the climate may change significantly in some regions, while for some other regions the impacts may not be remarkable. Therefore, the evaluation of the future wind climate based on regional models can be considered to be a suitable option to find further details of the potential of wind power and its sustainability over the study area.

The Intergovernmental Panel on Climate Change (IPCC) is the body set up by the United Nations which provides assessments of climate change, adaptations, and potential future risks. As a world-leading program, it provided assessment reports including different scenarios embedded with socioeconomic conditions for the fourth assessment report (AR4) and representative concentration pathways (RCPs) for the Coupled Model Intercomparison Project Phase 5 (CMIP5). Therefore, many different global circulation models (GCMs) in light of CMIP5's reports and assumptions for different scenarios have developed respective RCPs. These GCMs provide atmospheric and oceanic variable simulations on a global scale with different spatial resolutions. Due to their universal identity, they usually neglect local topography, and subsequently a regionalization (downscaling) procedure is employed for local studies. Generally speaking, there are two common types of statistical and dynamical downscaling: the former one employs statistical techniques to find relationships between the outputs of the GCMs with those of the observed or reference data representing the real characteristics of the climate in the desired area. The latter approach proceeds by applying the boundary conditions from the GCMs to run regional climate models (RCMs) considering physics and regional conditions operating at the local scale. Dealing with GCM wind data, as the near-surface wind speed usually follow a Weibull distribution, some researchers have developed Weibull-based downscaling techniques to modify the climatic wind data [1-3]. However, in the statistical techniques, effort is devoted to modifying the GCM wind data distribution toward a reference or observed wind data distribution, keeping the spatial or temporal resolution the same. Moreover, the statistical models, which only deal with the wind speed, suffer from modifications of the wind direction, which plays an important role in turbine operation and wind energy studies. On the other hand, dynamical approaches are employed to create higher-resolution outputs using the GCM simulations, regional observations, and boundary conditions. Therefore, they can provide more physically sound predictions of the parameters in the study area than the statistical techniques, although their complexity and cost are higher.

To downscale wind outputs to a finer resolution, weather research and forecasting (WRF) is a commonly used method to generate regional climate models. WRF has been frequently used for the dynamical downscaling of wind data from different sources such as ERA-40 [4], ERA-Interim [5], GCM outputs [6], and observatory stations [7]. Recently, the coordinated regional downscaling experiment (CORDEX) — as a world climate program to develop and improve regional climate models (RCMs) - has garnered increased popularity. The program provides freely available simulations of the climate variables for different domains or regions with higher resolutions. In other words, the CORDEX-based models generate regional climate models based on the boundary conditions of the GCMs and also by employing both dynamical downscaling and statistical techniques. The results of previous studies demonstrated good consistency between CORDEX wind outputs and those of the reference data, and subsequently future simulations of CORDEX have been applied for regional climate projections in different areas [8-11].

There are a large number of studies assessing the potential of wind energy and its distribution for different areas, indicating the suitability of this kind of energy to meet power demand [12,13]. Additionally, separate studies have addressed the explored features of offshore wind power including the impacts of air density fluctuations, transmission systems, electrical topography, etc. [14-16]. It was shown that innovative solutions dealing with turbines, such as a lubrication system for hollow roller 
bearings, can lead to increased energy efficiency and system output [17,18]. Different algorithms have been employed to find the optimal layout of wind farm and placement of wind turbines for different regions $[19,20]$. Furthermore, impacts of climate change on wind energy resources have been evaluated using different GCMs and also regional climate models for different areas all over the world. Using three different GCMs, it was found that the wind energy under future climatic conditions in the eastern half of Taiwan Strait will slightly decrease. Moreover, it was found that the energy density in the eastern half of the Strait is higher than the other part [1]. Considering the European domain with a focus on the Black Sea, results of a research study using CORDEX outputs to illustrate climate change impacts on future wind energies projected a general trend of decrease for majority of the regions [21]. There are similar studies projecting climate change impacts on the wind energy in other regions such as California [22] and Ontario [23].

This study mainly aimed to evaluate and explore wind power potential and its variability under future climatic conditions. In this regard, three regional climate models from MENA-CORDEX simulations of near surface wind have been taken for climate change impact studies. The Persian Gulf was selected as a case study to project wind climate and its spatial distribution therein. Ensemble model combining outputs of three RCMs was considered to detect the general trend related to the climate change impacts on the wind climate variability. Results of the models in terms of mean annual, mean seasonal, and directional variability for the present and future scenarios of RCP4.5 were analyzed for selected energy hotspots as tentative places for energy extraction.

\section{Materials and Methods}

\subsection{Study Area}

The Persian Gulf is a fast-growing area surrounded by Iran and six Arabian countries of Iraq, Kuwait, Saudi Arabia, Bahrain, Qatar, and United Arab Emirates. Its bathymetry changes from shallow in the southern stripe to relatively deeper areas in the middle and northern of the Gulf. Figure 1 presents bathymetry of the study area. The Gulf is extended to the Oman Sea through its narrowest part called Hormoz Strait which is the gateway for one-fifth of the world oil industry. Due to its strategic position, it is experiencing an increasing growth in population, industry, and infrastructures that necessitates an enhanced demand in the energy sector. Its overall shallow depth (average about $50 \mathrm{~m}$ ) which rarely exceeds $90 \mathrm{~m}$ in offshore regions provides a suitable potential to develop and install wind turbines for wind energy purposes. The dominant wind regime affecting the middle and northwest of the Gulf is Shamal winds blowing over the area mainly in winter and summer [24]. Seasonal variability of wind power resources and its spatial distribution should be taken into consideration for any development in the wind energy sector. The bathymetry data were obtained from the General Bathymetric Chart of the Oceans (GEBCO) with a spatial resolution of 30 arc-seconds. The bathymetry data are accessible from the following link: https://www.gebco.net/data_and_products/gridded_bathymetry_data/. 


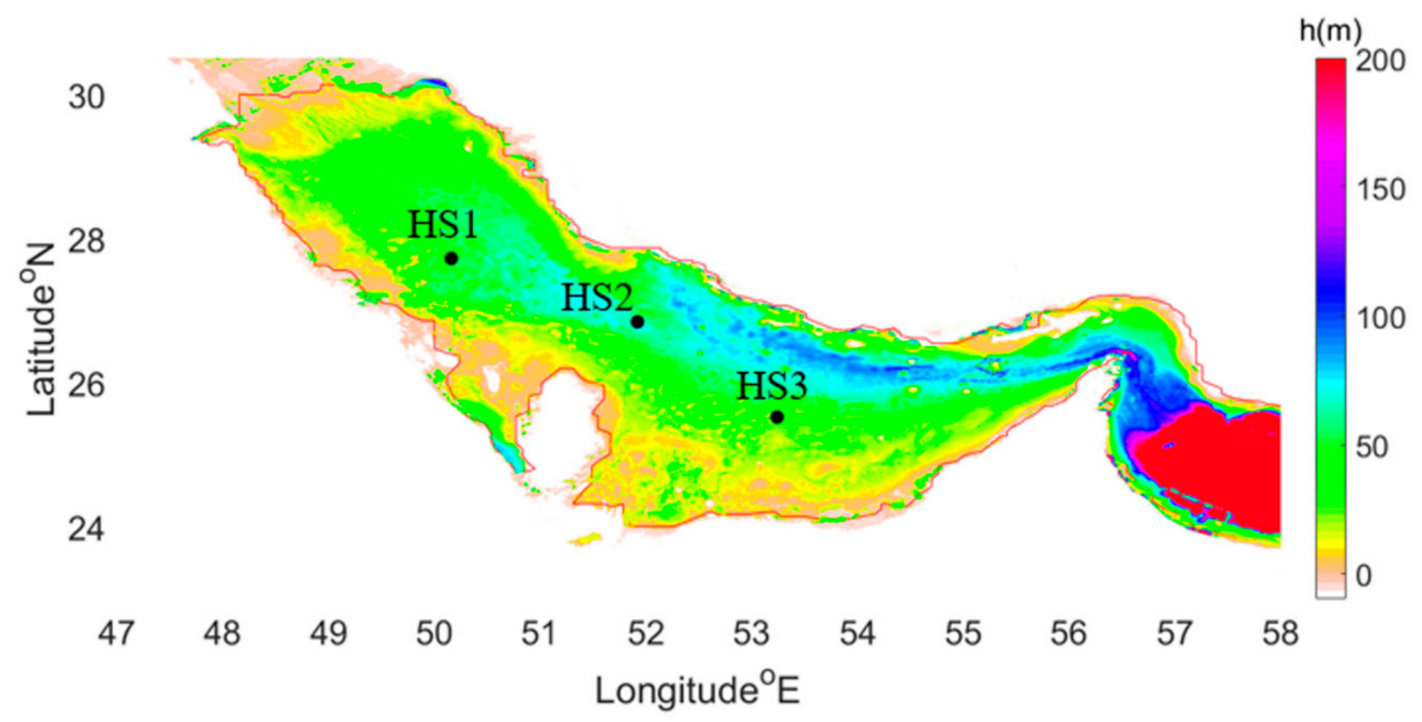

Figure 1. Study area and bathymetry variation.

\subsection{CORDEX Wind Simulations}

To evaluate wind power potential and its future variability under climate change impacts, it is common to employ near surface wind speed from available GCMs or RCMs. For that purpose, this study uses three regional climate models obtained from CORDEX simulations which have higher resolution than GCMs. Moreover, they were downscaled using different dynamical and statistical techniques. Therefore, there is no extra effort for data regionalization. As the study area is located in the Middle East, CORDEX outputs for domain of Middle East and North Africa (MENA) were taken into consideration. For this domain, only three RCMs including CNRM, EC-EARTH, and GFDL (all with spatial resolution of $0.44 \times 0.44^{\circ}$ ) were available in daily time scale and subsequently all of these three RCMs were used. CNRM has been developed by Centre National de Recherches Meteorologiques in France, EC-EARTH is a European community Earth-System Model, and GFDL is referred to as the Geophysical Fluid Dynamics Laboratory which is one of the seven research laboratories of National Oceanic and Atmospheric Administration (NOAA). The data were obtained for the historical period of 1981-2000 and future period of 2081-2100. The selected historical period is the common period for all the three RCMs. Moreover, the climate change studies usually consider future variations after 100 years from the historical one. Dealing with future datasets, they are available for different scenarios indicating different representative concentration pathways of RCP2.6, RCP4.5, RCP6, and RCP8.5. Generally, RCPs are greenhouse gas concentration trajectories that have been presented and substituted with the former socioeconomic scenarios in the fifth assessment report. These concentration pathways represent a possible range of radiative forcing values for the year 2100 in Watt per square meter. RCP2.6 and RCP8.5 were considered as the optimistic and pessimistic scenarios, respectively. RCP4.5 and RCP6 are intermediate scenarios in which RCP4.5 and RCP8.5 are more common scenarios than the others for climate change studies. Thus, in this study, RCP4.5 was chosen as an intermediate and common scenario used to project future variation of wind power. Concerning to climatic data, it is a common task to evaluate their consistency with a reference data that has formerly been successfully applied for the study area. In this regard, ERA-Interim reanalysis data obtained from ECMWF (European Center for Medium Weather Forecasts) was used to check consistency and accuracy of the RCMs during the historical period. Figure 2 illustrates mean annual wind speeds over the study area for ERA-Interim and three RCMs during 1981-2000. 

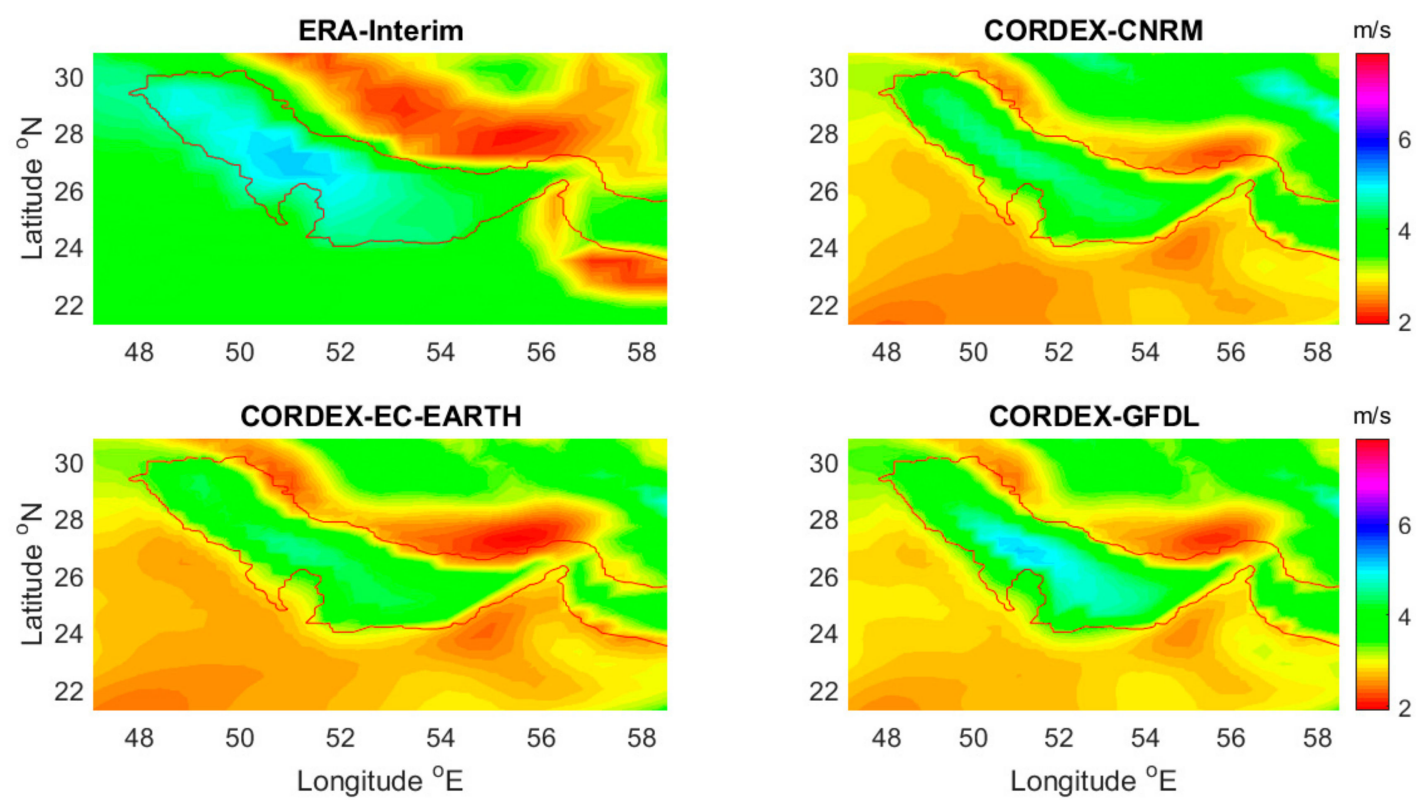

Figure 2. Mean annual near surface wind speed for historical period.

According to Figure 2, RCMs have roughly similar values in terms of mean annual wind speed while the GFDL model provides slightly higher values in the middle part of the Gulf. Comparing wind speed of the CORDEX simulations with those of the ERA-Interim, good agreement of similarities can be found for nearshore and offshore regions even though for surrounding land, the wind speeds of the RCMs are a little bit different from the corresponding values of ERA-Interim. However, this study is going to focus on sea area not land territory. Therefore, the CORDEX simulations can be reliably employed to project present and future wind power distribution. Considering the RCMs, the outputs of GFDL has a better consistency with the ERA-Interim in the middle part of the Gulf while for onshore regions, EC-EARTH showed higher similarity. However, to have a quantitative assessment of the wind climate obtained from different models, Table 1 provides mean annual wind speed (Avg.), minimum (Min.), maximum (Max.), and standard deviation (Std.) of different models averaged over the whole study area and during the historical period.

Table 1. Statistics of wind speed in $\mathrm{m} / \mathrm{s}$ obtained from different models over the whole area during 1981-2000.

\begin{tabular}{ccccc}
\hline Model & Min. & Max. & Avg. & Std. \\
\hline ERA-Interim & 1.90 & 5.16 & 3.60 & 0.75 \\
CORDEX-CNRM & 2.08 & 7.13 & 3.37 & 1.13 \\
CORDEX-EC-EARTH & 1.95 & 7.87 & 3.40 & 1.24 \\
CORDEX-GFDL & 2.10 & 7.77 & 3.47 & 1.21 \\
\hline
\end{tabular}

Regarding Table 1, it is derived that the RCMs have relatively similar statistics even though their maximum has higher differences. Among the RCMs, EC-EARTH and GFDL have closer values to each other in terms of average, maximum, and standard deviation. Comparing statistics of the RCMs with those of ERA-Interim, it can be found that the RCMs generally underestimate wind speed as they have a lower average over the whole area. Moreover, the RCMs have higher values of maximum and standard deviation which indicated their higher variability over the average. However, the statistics presented in Table 1 reveal that there is a good consistency between the RCM simulations and ERA-Interim. Therefore, the RCMs can be applied for further investigations in the study area. 


\subsection{Wind Energy and Multi-Model Ensemble}

Wind power is generally computed at the turbine hub-height (90-120 m or higher). However, as the climatic wind data and also reference data are available for $10 \mathrm{~m}$, therefore, the wind speed for power calculations should be converted to the desired height usually called turbine hub-height. In this regard, it is necessary to extrapolate $10 \mathrm{~m}$ wind speed to turbine hub-height using available equations. The extrapolation can be carried out by employing a logarithmic profile for wind speed as:

$$
W_{z}=\frac{u_{*}}{k} \ln \left(\frac{z}{z_{0}}\right)
$$

where $W_{z}$. is the wind speed $(\mathrm{m} / \mathrm{s})$ at height $\mathrm{z}$ in meters, $u_{*}$. is the shear velocity $(\mathrm{m} / \mathrm{s}), k=0.4$, and $z_{0}$. is roughness length $(\mathrm{m})$. The shear velocity can be formulated as a function of surface wind stress $(\tau)$ in $\mathrm{N} / \mathrm{m}^{2}$ and air density $\left(\rho_{\text {air }}\right.$. ) as:

$$
u_{*}=\sqrt{\frac{\tau}{\rho_{\text {air }}}} .
$$

To compute wind speed at the desired height, shear velocity and surface roughness are unknown in that they have to be determined carefully. Moreover, air density and its seasonal variability play an important role in wind power computations. It was found that air density correction in winter and summer can make by $8 \%$ difference in wind power computations [25]. Due to the complexity and seasonal variability in effective parameters on the shear velocity, the following equation can be applied to convert near surface wind speed to the hub-height speed as

$$
\frac{W_{z}}{W_{\text {ref }}}=\frac{\ln \left(\frac{z}{z_{0}}\right)}{\ln \left(\frac{z_{\text {ref }}}{z_{0}}\right)},
$$

where $W_{r e f}$ denotes the wind speed at a reference level $\left(z_{r e f}\right)$, in this study meaning at $10 \mathrm{~m}$. Therefore, having roughness length for the study area, the wind speed at the desired level can be computed. As mentioned, roughness length can be calculated from we characteristics in offshore regions as [26]

$$
\frac{\mathrm{z}_{0}}{H_{s}}=1200\left(\frac{H_{s}}{L_{p}}\right)^{4.5}
$$

where $H_{s}$ and $L_{p}$ are significant wave height and wave length of the peak wave in meters, respectively. As we know, for deep waters, the wave length $(\mathrm{L})$ is only a function of wave period $(\mathrm{T})$ :

$$
L=1.56 T^{2} \text {. }
$$

In this study, near surface wind speed was extrapolated to turbine hub-height wind at $120 \mathrm{~m}$ using Equations (3)-(5) and mean significant wave height and period for a 20-year period to calculate roughness length. Finally, wind power $\left(\mathrm{W} / \mathrm{m}^{2}\right)$ can be derived as

$$
P=\frac{1}{2} \rho_{\text {air }} W_{z}^{3}
$$

where air density can change according to the regional conditions. According to a detailed study on the air density in the Persian Gulf, it was found that the density is changing in a range of $1.15-1.23 \mathrm{~kg} / \mathrm{m}^{3}$ [27]. In this study, an average value about $1.18 \mathrm{~kg} / \mathrm{m}^{3}$ was considered as air density over the whole study area. It is noticed that this study is mainly organized to investigate climate change impacts on wind power and, therefore, if some assumptions were made for computations, they are for both historical and future periods in which the errors of them can be neutralized or neglected. Equal weights were assigned for each RCM to build the ensemble model. Moreover, dealing with 
climate change studies, it is most common to assign equal weights to the selected GCMs/RCMs as the future performance of the models are not known [21].

\section{Results and Discussion}

\subsection{Annual Variability}

The computed wind power over the study area using near surface wind speed from CORDEX outputs of three different models were analyzed to derive climate change impacts. In this regard, results of the RCMs projecting mean annual wind power for historical and future periods are illustrated in Figures 3-5.
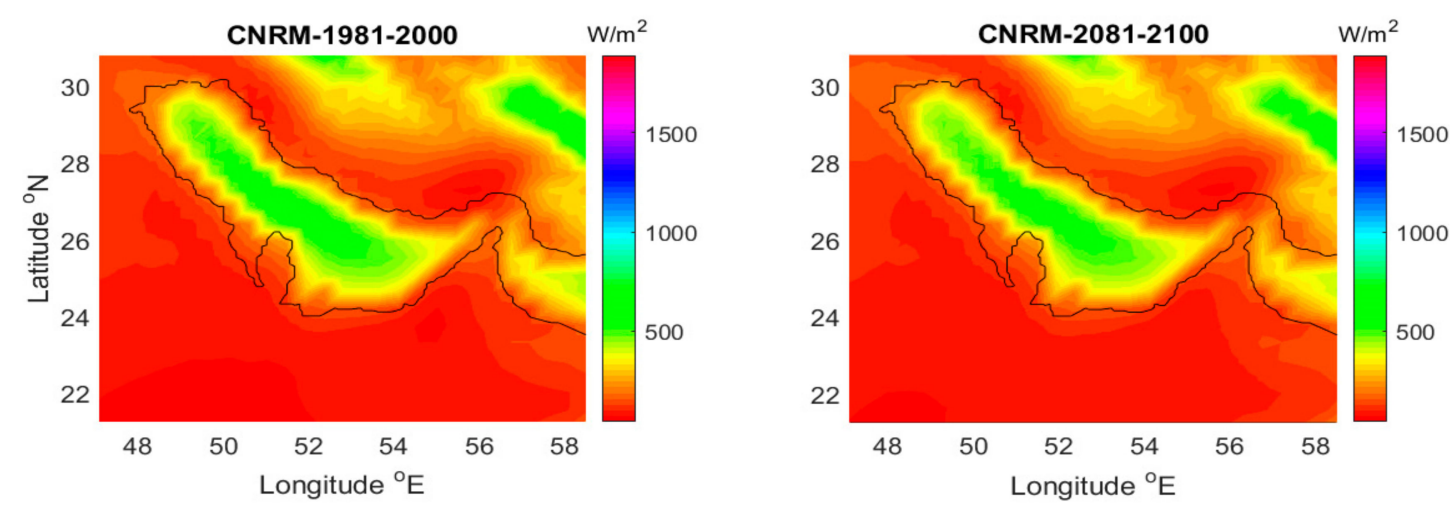

Figure 3. Mean annual wind power projection for CNRM-RCM.
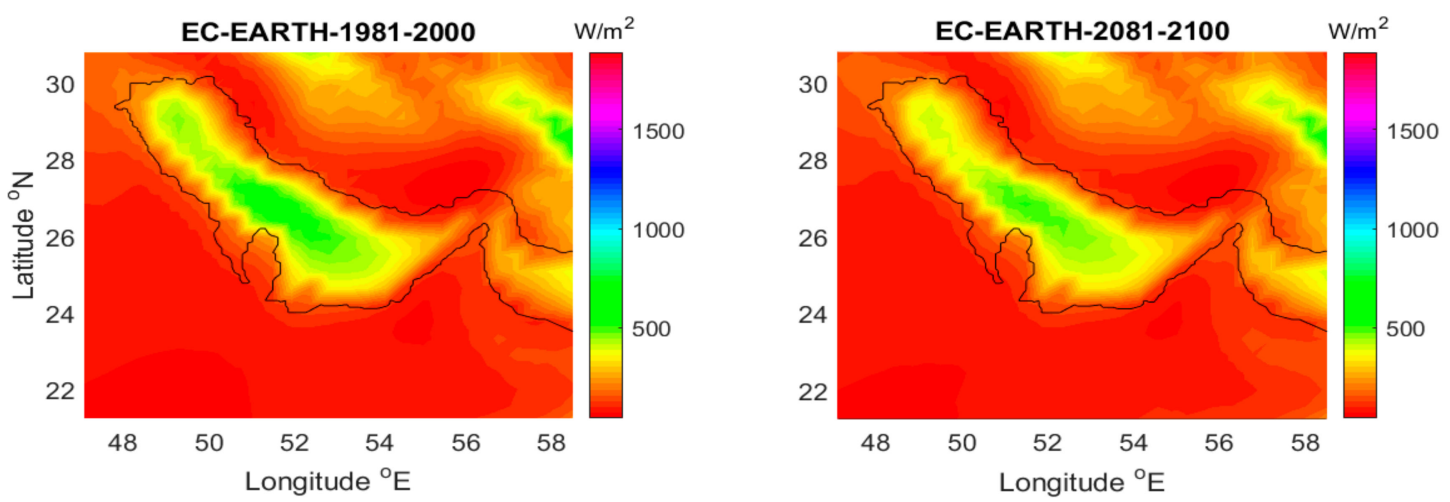

Figure 4. Mean annual wind power projection for EC-EARTH-RCM.
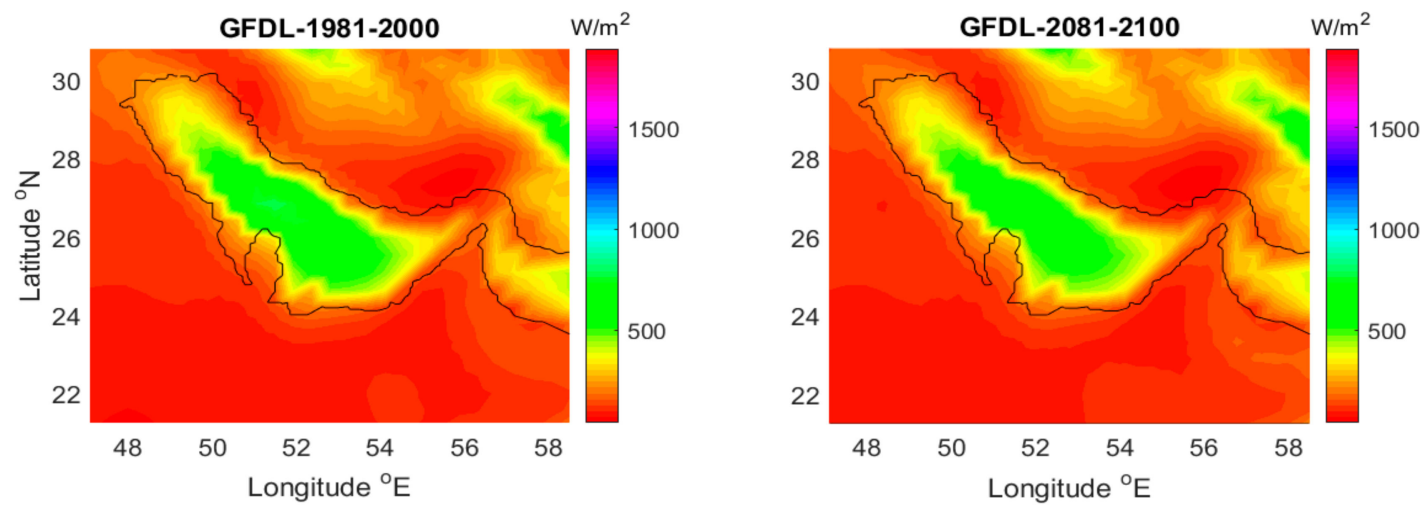

Figure 5. Mean annual wind power projection for GFDL-RCM.

According to Figure 3, the historical and future projections of wind power have roughly similar spatial distribution and it can be inferred that based on CNRM-RCM, the future wind power in terms 
of mean annual values does not change significantly. For lower latitudes far from the Gulf, a slight decrease in future wind power compared to those of the historical values can be observed. However, these regions are not the focus of the study.

Considering Figure 4 illustrating wind power simulations obtained from EC-EARTH-RCM, a decreasing trend for the future period can be detected by which this decrease is more highlighted in the northwest of the Gulf. On the other hand, for lower latitudes in the eastern part of the Gulf (out of the Gulf), future projections show relatively higher values of wind power than the historical period. The spatial distribution of the wind power for the present and future periods roughly follow the same pattern by which the peak power has a northwest to southeast direction with higher values in the middle parts of the Gulf. A similar pattern and result can be derived for the CNRM-RCM simulations as well.

Following Figure 5, it can be found that based on GFDL-RCM, there should not be a remarkable variation in the future wind power over the study area compared with the present climate. It means that the climate change does not affect the wind power distribution in the area significantly. For both of the historical and future periods, the middle part of the Gulf is the most powerful region which can be investigated for energy extraction purposes. To provide more robust conclusions, Figure 6 projects results of the ensemble model obtained from equal weighting of the RCM.
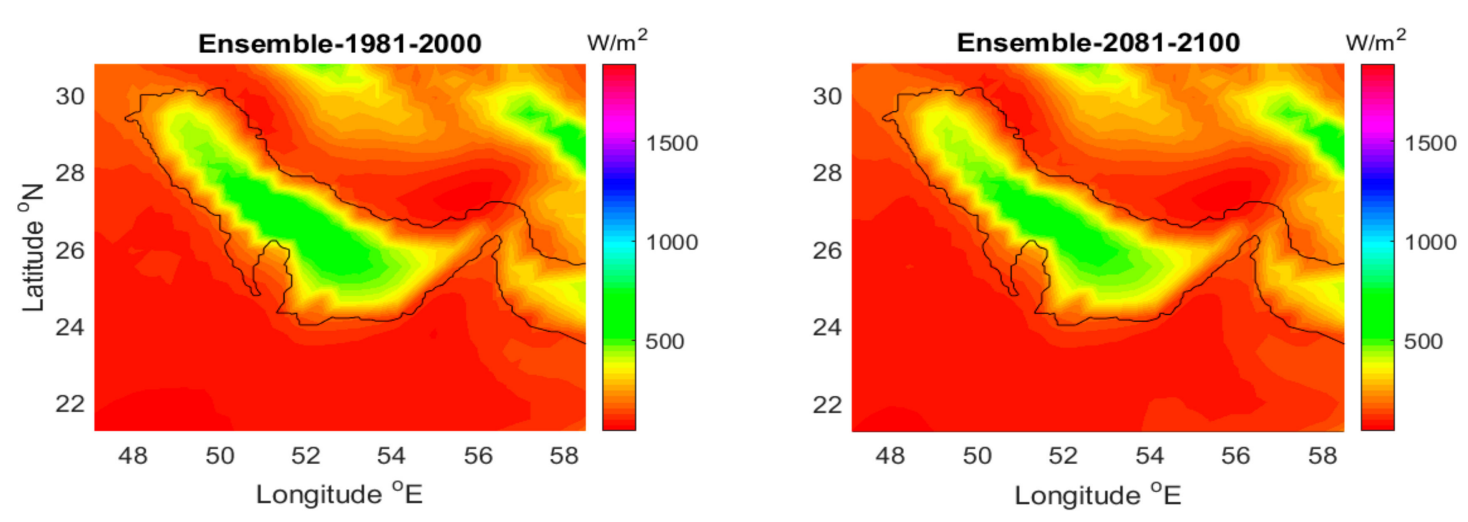

Figure 6. Mean annual wind power projection for the ensemble model.

Regarding Figure 6, it is derived that the wind power for both periods do not differ remarkably which indicates climate change and future warming conditions do not affect the wind power distribution over the study area considerably. Similar spatial distribution and pattern for the spatial variability for both historical and future periods reveal that the regions with higher potential for energy extraction will remain the same. This is an interesting point dealing with sustainable development by which the current energy hotspots will remain as the future energy hotspots. Therefore, the present design and construction of the wind farm can be efficiently used for future energy supply purposes. Generally speaking, wind turbines are installed in some points with higher potential for energy extraction and more efforts are devoted to analyzing the results for tentative energy hotspots. In this regard, further explorations were concentrated on the selected hotspots to provide more details of the present and future variability of the wind power in the area. According to the previous illustrations which unanimously demonstrated that the middle part of the Gulf is the most powerful region over the Gulf, three points as tentative hotspots were selected for further investigations. These energy hotspots are marked as HS1, HS2, and HS3 in Figure 1. Mean annual wind power for historical and future periods obtained from the ensemble model along with their geographical coordinates are given in Table 2. 
Table 2. Mean annual wind power for selected energy hotspots.

\begin{tabular}{ccccc}
\hline \multirow{2}{*}{ Point No. } & \multirow{2}{*}{ Long. $\left({ }^{\circ}\right)$} & Lat. $\left({ }^{\circ}\right)$ & \multicolumn{2}{c}{ Mean Annual Wind Power $\left(\mathbf{W} / \mathbf{m}^{\mathbf{2}}\right)$} \\
\cline { 3 - 5 } & & & Historical & Future \\
\hline 1 & 50.16 & 27.72 & 531.60 & 502.89 \\
2 & 51.92 & 26.84 & 619.22 & 571.14 \\
3 & 53.24 & 25.52 & 525.63 & 495.64 \\
\hline
\end{tabular}

Due to higher values of wind power in the middle part of the Gulf, the energy hotspots were selected at the middle part for further investigations. Table 2 presents mean annual wind power from the ensemble model for the historical and future periods. As derived from the table, the energy hotspots will experience a decrease under the future climatic scenario. The wind power considering RCP4.5 will decrease about $5 \%, 8 \%$, and $6 \%$ for hotspots 1 to 3 compared with the corresponding values in the historical period. However, this decrease is not valuable in terms of energy extraction and the results are promising toward energy sustainability in the study area. However, dealing with climate change studies, temporal variability of the energy resources in terms of interannual and seasonal variability play a vital role as there should be a balance between energy demand and energy supply. Therefore, temporal distribution of the wind power is required toward sustainable development in energy facilities and infrastructures. Moreover, the interannual analysis can present useful information if the future variations are because of natural fluctuations of the system or due to climate change impacts.

\subsection{Interannual Variability}

Interannual variability of wind power can illustrate wind power variation in a yearly time scale. More interestingly, in climate change impact studies, it can reveal the future yearly variation pattern versus historical period to get more insights of the temporal power distribution. In this regard, interannual projection of wind power for the three selected hotspots was carried out to analyze their variability and pattern over projection years. The results for the historical period (solid line) and for the future RCP4.5 scenario (dashed line) obtained from the ensemble model and also from the three RCMs are presented in Figures 7-9. In these figures, the horizontal axis denotes projected year numbers from 1 to 20, that for historical and future periods include 1981-2000 and 2081-2100, respectively.

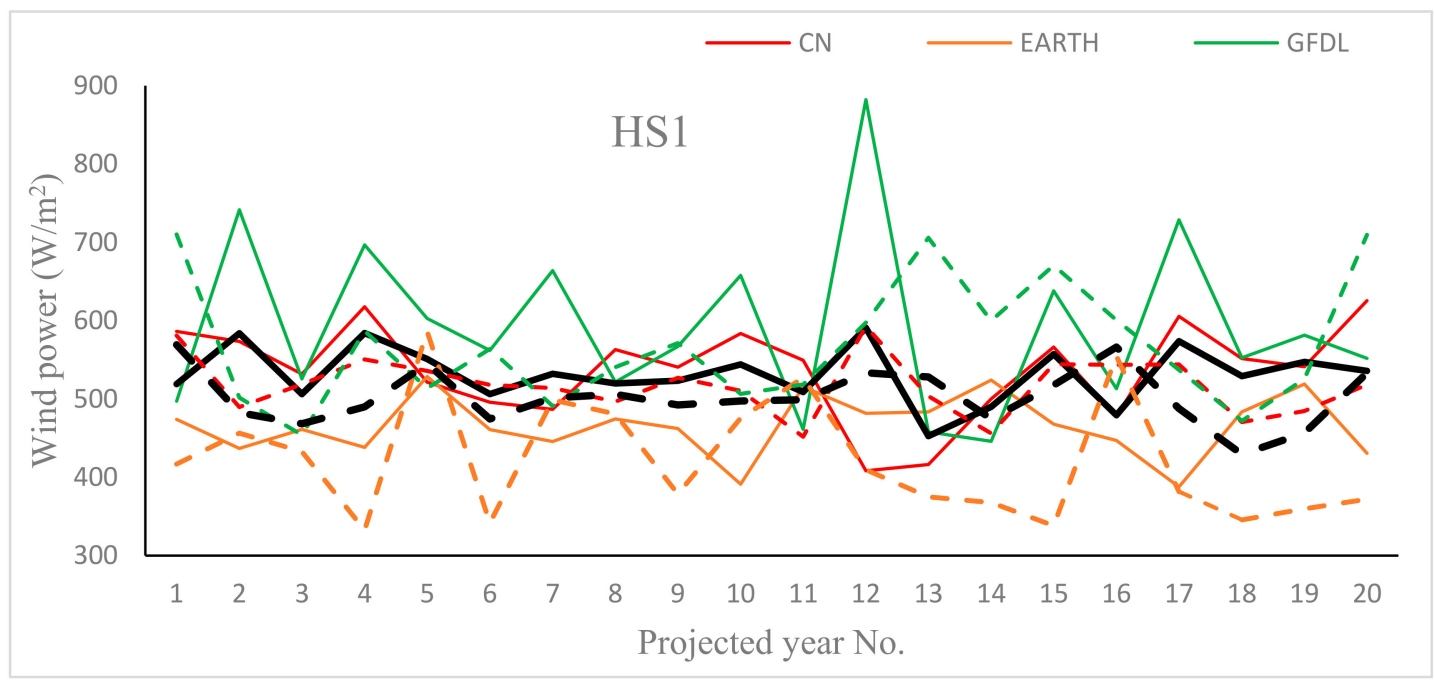

Figure 7. Interannual variability of wind power for energy hotspot 1. 


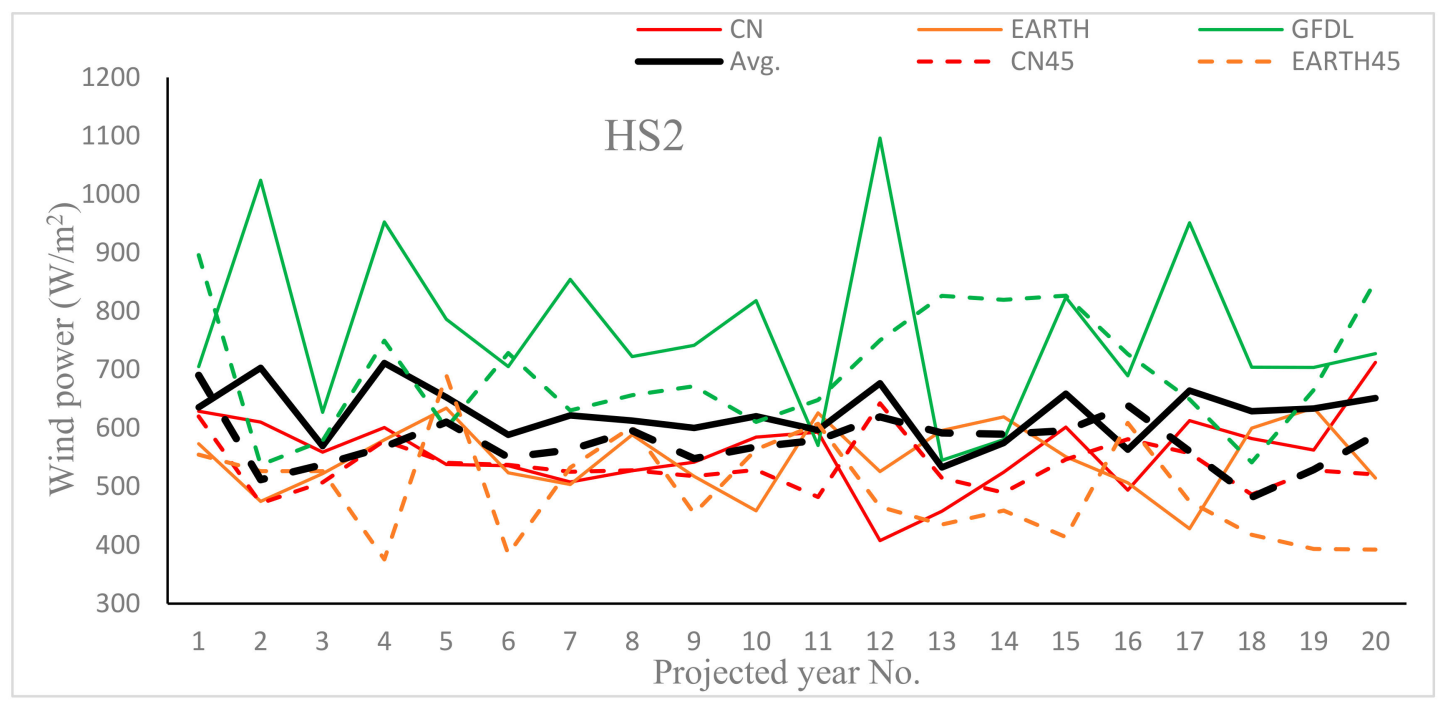

Figure 8. Interannual variability of wind power for energy hotspot 2.

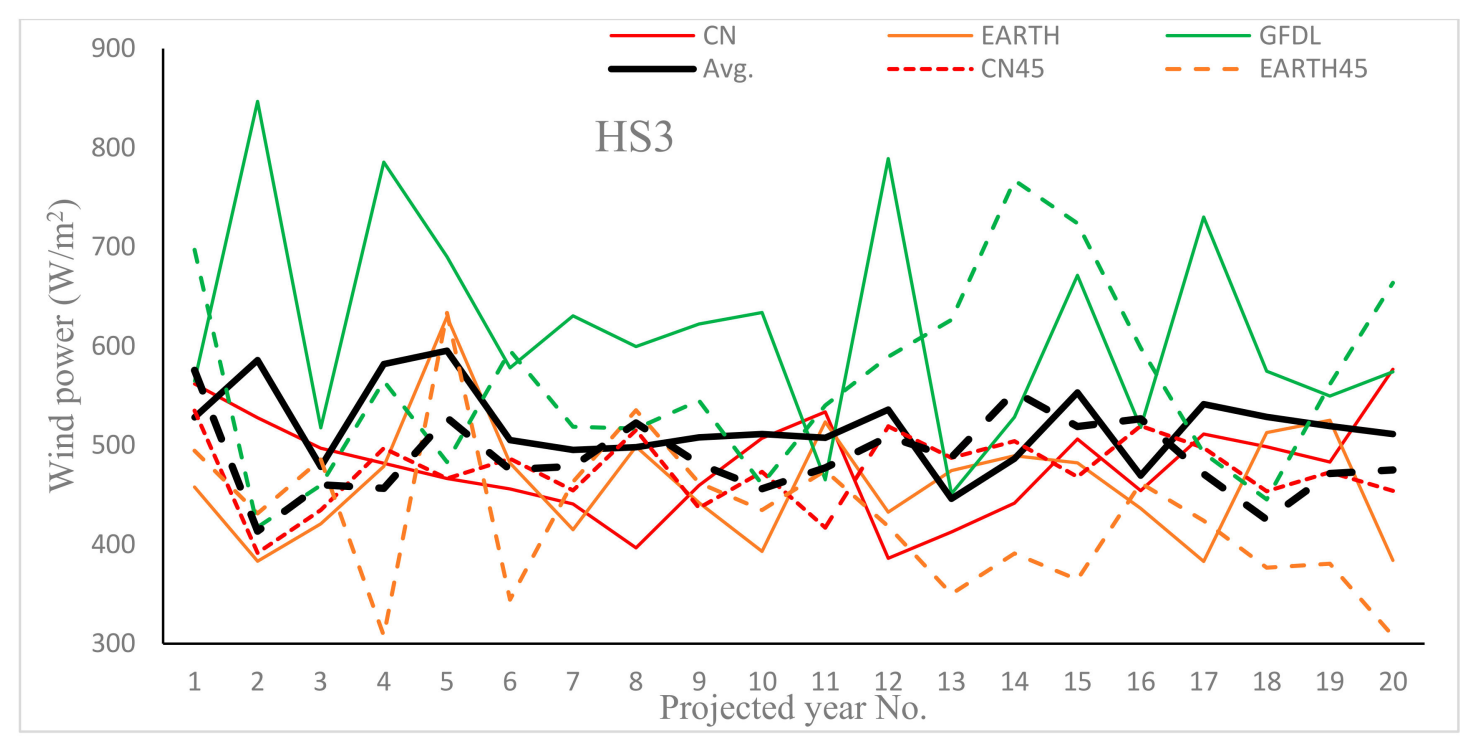

Figure 9. Interannual variability of wind power for energy hotspot 3.

As presented in Figure 7, the ensemble model provides a roughly uniform pattern for historical and future periods indicating a mild decrease in wind power for hotspot 1 . A similar result for each RCM can be derived but with slight fluctuations that can be neglected. Among the three RCMs, GFDL projects higher values and EC-EARTH provides lower values for wind power compared with the CNRM. However, from all the RCMs and also from the ensemble model, it can be inferred that the wind power density under future climatic conditions tends to slightly decrease compared to its corresponding values in the past. During 1981-2000, the wind power changes in a range of 500-600 W/m $\mathrm{m}^{2}$ in which for 2081-2100 the upper limit remains the same while the lower limit falls lower than $450 \mathrm{~W} / \mathrm{m}^{2}$. Regarding the RCMs, mean values obtained from CNRM showed less fluctuations while for the values for the two other RCMs increased and decreased with higher intensity. For the second decade, there are some sporadic years indicating higher values of wind power than its corresponding values in the past. However, it does not exceed the historical values remarkably. The interannual variability of the wind power is roughly less than $20 \%$ of the 20 -year average of the power which can be promising toward its sustainability and suitability for the operational purposes.

Considering Figure 8, hotspot 2 has stronger wind power than hotspot 1 in a way that its mean values for the historical period varies from 600 to $700 \mathrm{~W} / \mathrm{m}^{2}$ implying suitable potential of the place 
for wind energy extraction. Moreover, the corresponding values for the future period do not differ significantly from the past although they are slightly lower in most of the projected years. Concerning variability in RCM simulations, similar conclusions as hotspot 1 can be derived. Comparing the wind power potential for hotspots 1 and 2 implies stronger potential for the latter point than the former one.

In line with the previous figures depicting interannual variability of wind power for hotspots 1 and 2, Figure 9 shows a similar trend in which future power will decrease slightly under climate change impacts. However, the magnitude of this decrease is not valuable or does not influence operation or efficiency of the plan. For hotspot 3, the interannual variability is slightly higher than other points demonstrating stronger fluctuations in the mean annual wind power for the point. However, its magnitude is still acceptable for practical applications of energy extraction and exploitation. Therefore, interannual variability analysis for historical and future conditions presents suitable potential for wind energy extraction plans in the study area. Among the three hotspots, hotspot 2 has the highest values which may be because of its deeper water and less disturbance from the local topography. For this point, the power changes in a range about $600-700 \mathrm{~W} / \mathrm{m}^{2}$ while for the other points it is about $500-600 \mathrm{~W} / \mathrm{m}^{2}$.

Seasonal variation in energy demand for areas such as the countries surrounding the Persian Gulf is common because of seasonal weather changes. For example, the hot summer enhances the need for electricity drastically. Moreover, to employ wind power potential for practical applications, the wind power and its distribution for different seasons should be assessed sufficiently. It is an important stage toward sustainable development and operation of the energy system and also to meet sustainable development requirements. The results of seasonal analysis for wind power in the three hotspots in the Persian Gulf are presented in the following subsection.

\subsection{Seasonal Variability of the Energy Hotspots}

The results of each RCM for historical and RCP4.5 scenarios were seasonally separated and subsequently they were averaged to compute mean wind power for the three hotspots as an ensemble model. Table 3 gives wind power outputs of the ensemble model for each hotspot and also for each season.

Table 3. Mean seasonal variability of wind power $\left(\mathrm{W} / \mathrm{m}^{2}\right)$ in the selected hotspots.

\begin{tabular}{ccccccccc}
\hline \multirow{2}{*}{ No. } & \multicolumn{2}{c}{ Winter } & \multicolumn{2}{c}{ Spring } & \multicolumn{2}{c}{ Summer } & \multicolumn{2}{c}{ Autumn } \\
\cline { 2 - 8 } & Historical & Future & Historical & Future & Historical & Future & Historical & Future \\
\hline 1 & 370.45 & 355.49 & 239.23 & 229.44 & 218.64 & 187.67 & 283.85 & 275.96 \\
2 & 404.15 & 392.15 & 320.43 & 309.31 & 347.32 & 323.85 & 315.24 & 284.31 \\
3 & 547.02 & 530.45 & 256.78 & 247.32 & 322.53 & 299.81 & 317.25 & 300.10 \\
\hline
\end{tabular}

Generally, for all the seasons and for all the hotspots, the future wind power has lower values than the historical period indicating a decreasing trend under the future climate change scenario. However, rate of this decrease is not monotonic for all the seasons. Considering the seasonal variability, spring and summer can be recognized as the seasons with the lowest and highest variations, respectively. Moreover, seasonal distribution of wind power over the study area shows a strong spatial variability in which hotspot 3 has the highest wind power in winter and autumn while in spring and summer the highest values of wind power are obtained for hotspot 2 . The wind power on average decreases about $4 \%, 3 \%, 9 \%$, and $7 \%$ for winter, spring, summer, and autumn, respectively. Considering seasonal variations in each hotspot, the future wind power has a decrease about $6-8 \%$ in which the middle one (hotspot 2) has slightly higher variability amongst the others. All in all, it can be derived that spatial variability and also seasonal variability of wind power under the future climate condition of RCP4.5 does not differ more than $10 \%$ demonstrating wind energy sustainability over the study area and suitability of the region for future energy extraction planning and construction. 


\subsection{Directional Analysis of Wind Power}

Wind direction has a major effect on the efficiency and operation of wind turbine. It was found that small changes in the wind direction angle may have strong impacts on the total wind farm power output that a $10^{\circ}$ change in wind direction can change the energy output about $43 \%$ [28]. Along with this study, a separate study conducted on the wind farm in Germany showed high dependency of the power on the wind direction [29]. Therefore, directional analysis for energy hotspots in the present and also under future climate change scenarios should be carried out to provide more details for wind turbine design and installation purposes amongst others.

According to Figure 10, wind power in hotspot 1 has generally a northwestern direction in line with the dominant wind regime in the study area (so-called Shamal wind). Comparing future and historical wind power direction for this point demonstrates that the direction does not change significantly. However, the frequency of the wind power greater than $2 \mathrm{~kW} / \mathrm{m}^{2}$ for the future RCP4.5 will slightly decrease. Considering outputs obtained from the different RCMs, the direction for all of them roughly has the same pattern, even though frequency and magnitude are the same. However, it seems that CNRM has less sensitivity to changing climate than GFDL and EC-EARTH.

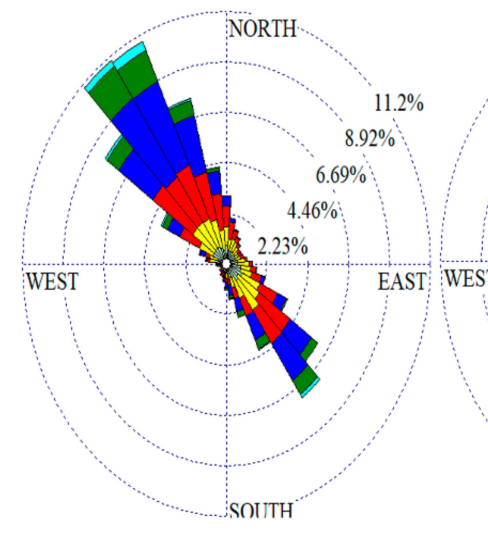

(a)

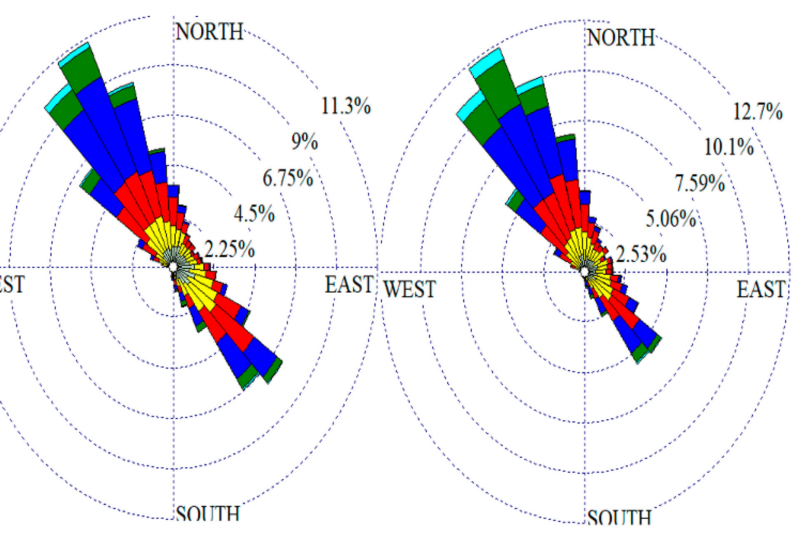

(b) (c)

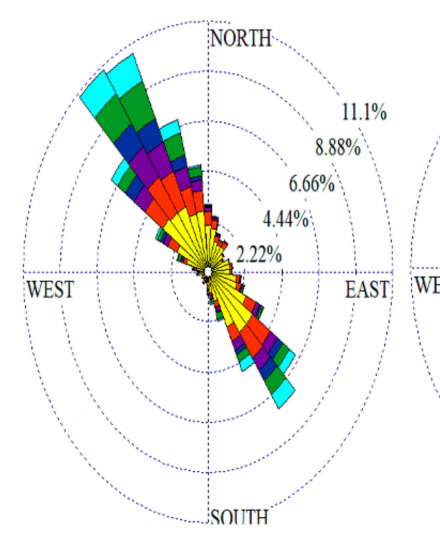

(d)

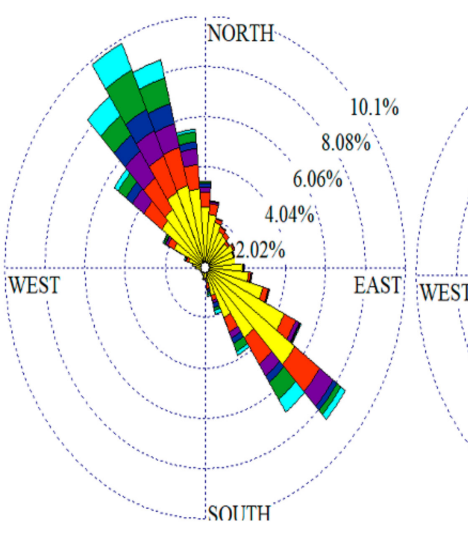

(e)

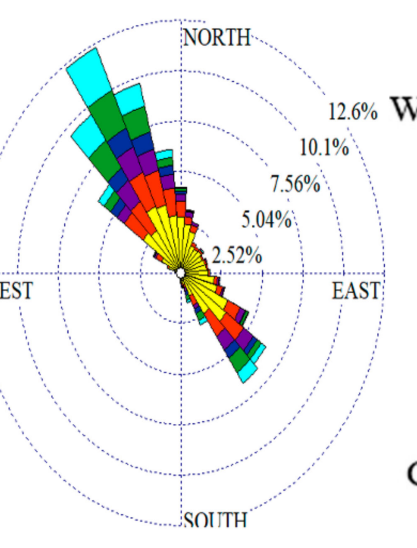

(f)

Figure 10. Wind power rose diagram for hotspot 1, historical simulations of (a) CN, (b) EARTH, (c) GFDL, and for future scenario of (d) CN45, (e) EARTH45, (f) GFDL45.

The second hotspot in the middle of the Gulf illustrated in Figure 11 has a similar pattern in directional distribution as the hotspot 1 with slightly higher values due to longer fetch blows over there. The dominant wind direction here is still northwestern which is mainly due to Shamal wind. Considering climate change impacts, the power directional distribution for CNRM remains the same as the historical one while GFDL and EC-EARTH show a slight decrease in the magnitude or frequency 
of strong winds. However, it can be clearly observed that frequency of the northwestern wind slightly decreases but the southeastern winds are increasingly blown for the future scenario.

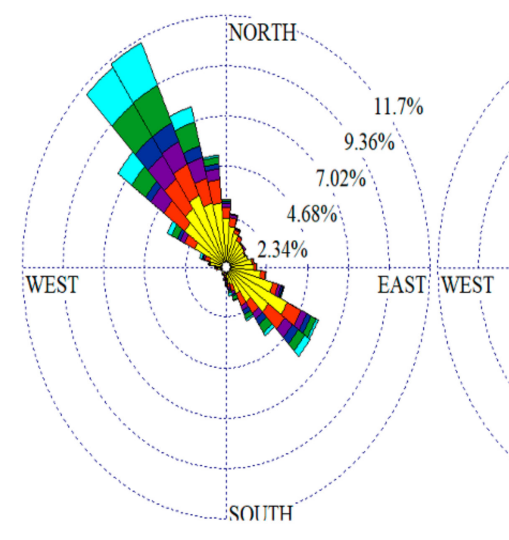

(a)

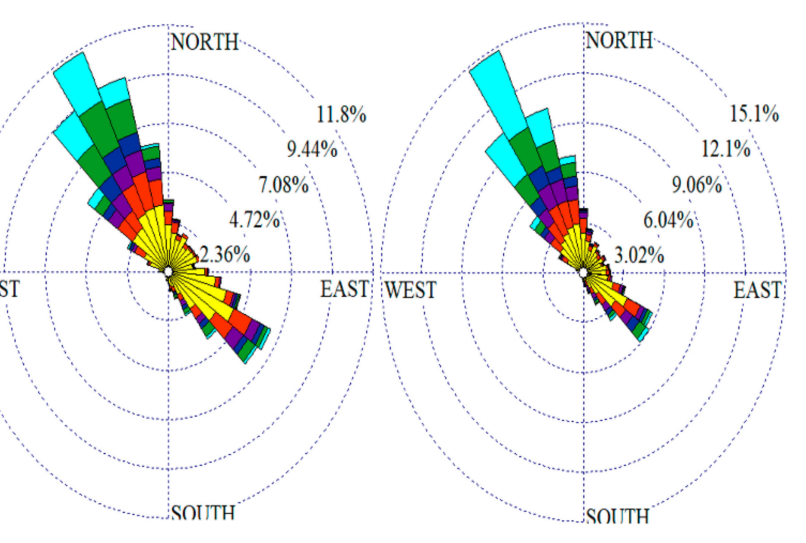

(b) (c)

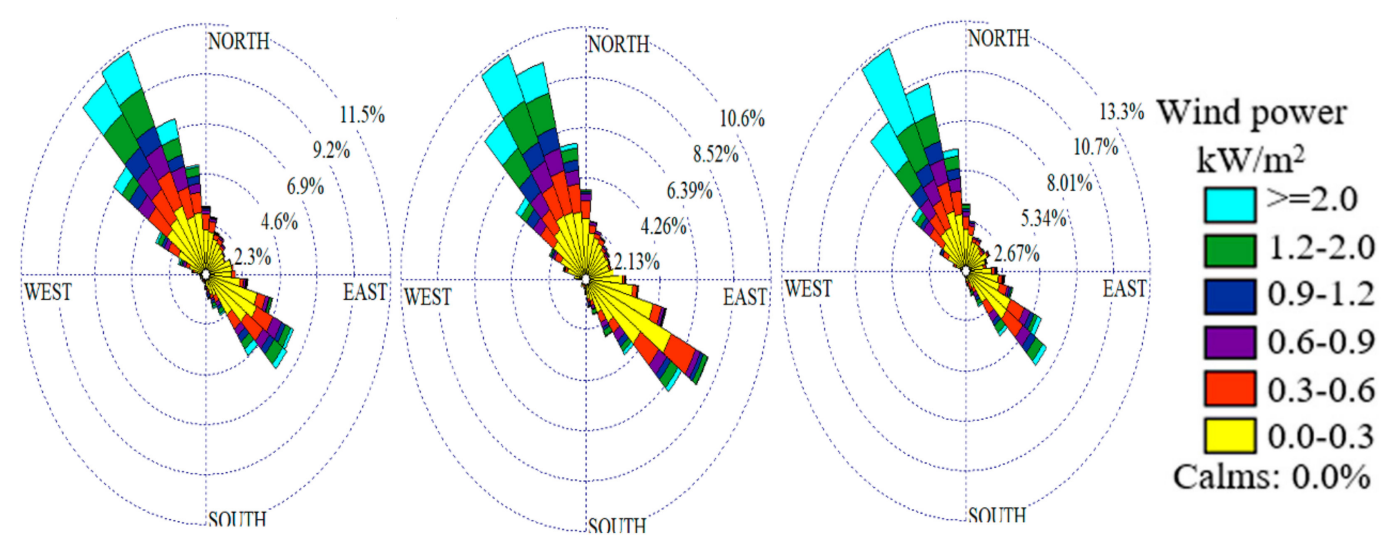

(d)

(e)

(f)

Figure 11. Wind power rose diagram for hotspot 2, historical simulations of (a) CN, (b) EARTH, (c) GFDL, and for future scenario of (d) CN45, (e) EARTH45, (f) GFDL45.

Considering Figure 12, similar conclusions for climate change impacts can be derived indicating that future simulations of wind power do not differ from the historical simulations in terms of the wind direction. However, it can be observed that the eastern winds are enhanced while the northwestern winds are slightly decreased. These results are valid for all the three RCMs considered in this study. A comparison among wind directions for three hotspots revealed that moving from northwest to southeast, impacts of eastern and southeastern winds will be enhanced while the effect of northwestern winds is attenuated. However, this change happens gradually along the Gulf. The main reason refers to the dominant wind regime which is more robust in northwest and middle parts of the Gulf and for other regions some other winds from different directions such as from eastern parts of the Gulf are highlighted. 


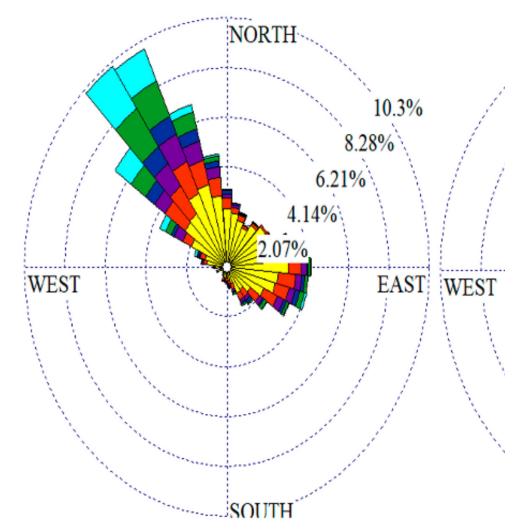

(a)

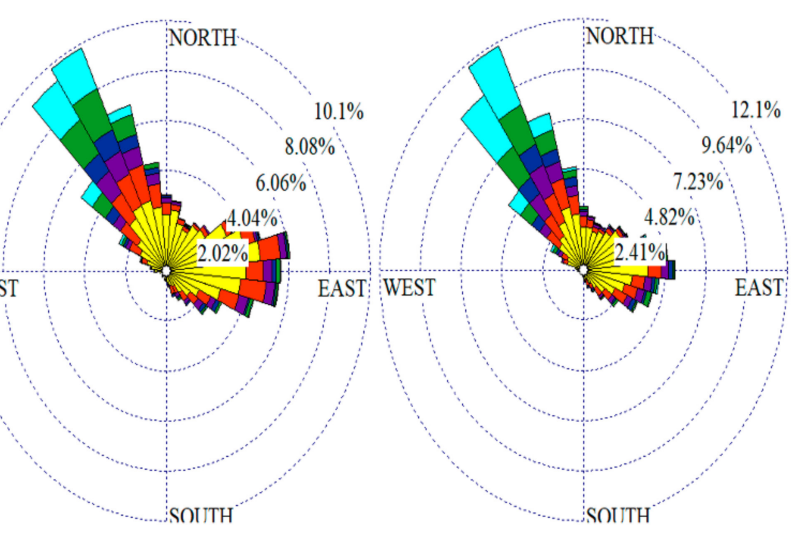

(b)

(c)

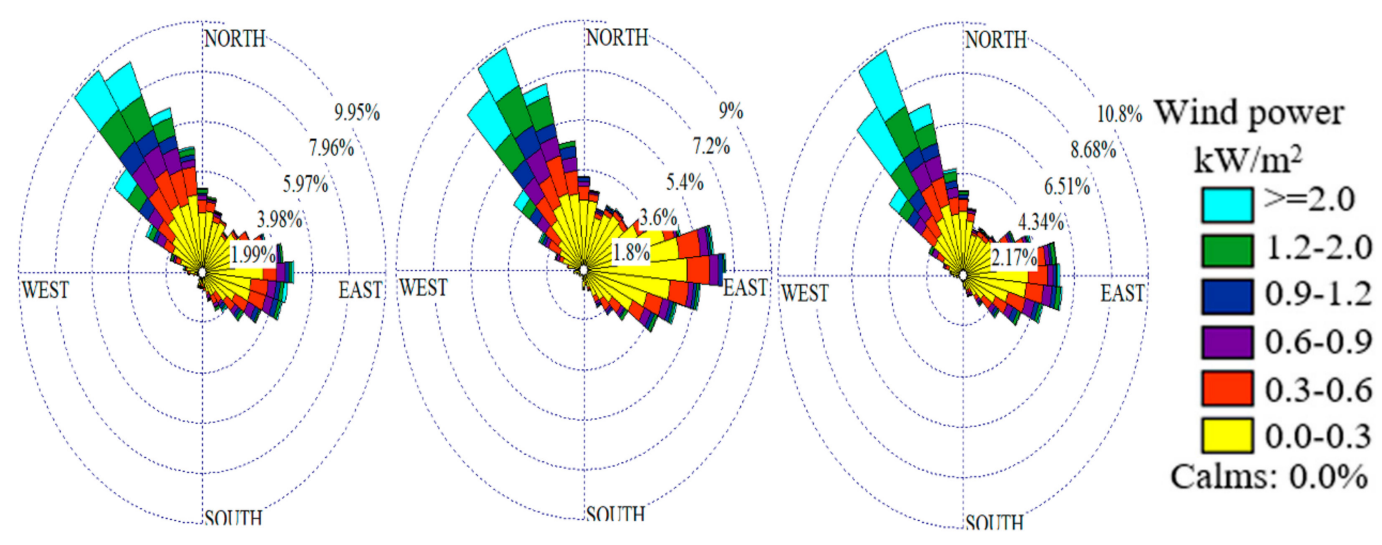

(d)

(e)

(f)

Figure 12. Wind power rose diagram for hotspot 3 , historical simulations of (a) $\mathrm{CN}$, (b) EARTH, (c) GFDL, and for future scenario of (d) CN45, (e) EARTH45, (f) GFDL45.

Generally, results of the directional analysis reveal that wind direction for the selected hotspots does not change remarkably which is consistent towards sustainable development and keeping the wind turbine efficiency as high as desired. However, it was found that intensity of the northwestern winds slightly decreases and on the other hand a mild increase in the southeastern and eastern winds can be expected due to climate change impacts on the wind power. The pattern of wind direction and its future variations are roughly the same for all the three RCMs taken into consideration.

\section{Conclusions}

Renewable energies are going to be employed as important and reliable alternative energy resources for fossil fuels which are traditionally in use. However, recently, due to increasing concerns regarding global warming and increasing greenhouse gas emissions, cleaner energy resources have caught much attention and gained popularity. Wind power constitutes a major part of renewable energy due to its worldwide distribution and availability. It is being increasingly used in European countries and for other regions, efforts have been devoted to establishing or increase currently available wind farms. However, due to importance of the climate change and future climatic conditions, it is necessary to evaluate its impacts on any renewable energy development or even to assess future variability of the available turbine. In this regard, this study was mainly organized to investigate climate change impacts on wind power distribution in the Persian Gulf as a fast-growing area with high demand for energy supply. In this regard, three regional climate models from CORDEX simulations including CNRM, GFDL, and EC-EARTH were taken into consideration for a 20-year period in 1981-2000 and the simulations of RCP4.5 for the future period of 2081-2100. The near surface wind speed of different 
climate models were checked in terms of consistency with those of ERA-Interim reanalysis data as reference wind speed. Afterwards, the wind speed at level $10 \mathrm{~m}$ was extrapolated to a typical turbine hub-height of $120 \mathrm{~m}$. Finally, the wind power density was computed and analyzed in terms of spatial, temporal, and directional variability.

Results of the consistency check to evaluate the performance of the CORDEX based regional climate models against the ERA-Interim as reference data revealed good similarity between two data resources. All the three RCMs have relatively similar mean annual wind speeds averaged over the whole area as the reference data. However, the RCMs slightly underestimate wind speed for the study area while representing higher extreme values and subsequently higher standard deviation. Moreover, it was found that outputs of different RCMs are close to each other indicating efficiency and high capability of the CODEX program to regionalize global climate models to generate regional models with higher resolution and better consistency with the regional climatic conditions.

Spatial distribution of wind power over the whole area revealed that the middle part of the Gulf has stronger wind power. Moreover, results of mean annual wind power illustrated that climate change impacts are not remarkable, by which the future projections of wind power had roughly the same magnitude as the historical values in terms of mean annual wind power for a 20 -year period. However, results obtained from the ensemble model showed that the future wind power for RCP4.5 slightly decreases but this decrease does not exceed $10 \%$ over the whole area. Along with the annual analysis, results of interannual variability for selected hotspots demonstrated a mild decrease for the future scenario but the decreasing rate was still insignificant. Similarly, a seasonal analysis for the hotspots in historical and future periods indicated a slight decrease in future projections with summer and spring as the seasons with the highest and lowest variations, respectively. Moreover, it was found that winter is the most powerful season while summer is the weakest season, which changes from point to point.

Directional analysis of wind power confirms that climate change has no remarkable impacts on the wind direction by comparing historical results with those of future scenarios. However, it can be found that a small decrease in the dominant wind direction (northwestern) and a mild increase in frequency and magnitude of southeast and eastern winds will probably happen during the future period. Considering spatial distribution of wind power direction, it is obtained that in the western half of the Gulf, the majority of the strong winds blow from the northwest while for the eastern half of the Gulf, both northwestern and eastern winds contribute to wind power production.

In conclusion, it can be found that the study area has an appropriate potential for energy extraction in the selected hotspots. Moreover, the directional analysis of wind power confirms suitability of the region for energy extraction purposes because of concentrating major energy in a special direction (mainly in northwest). In addition, climate change has no significant impacts on the energy resources which is promising toward sustainable development of energy facilities and infrastructures. Results of annual, interannual, seasonal, and directional analyses unanimously demonstrate sustainability of the wind power as a renewable energy resource. Therefore, findings of this study are promising to consider wind energy as a reliable and sustainable source of renewable energy for the Persian Gulf.

Author Contributions: Conceptualization, S.W. and H.Y.; methodology, S.W. and H.Y.; software, S.W., validation, H.Y. and Q.B.P.; formal analysis, Q.B.P.; investigation, Q.B.P.; data curation, Q.B.P.; writing—original draft preparation, D.N.K. and P.T.T.N.; writing-review and editing, D.N.K. and P.T.T.N. All authors have read and agreed to the published version of the manuscript.

Funding: This research received no external funding.

Conflicts of Interest: The authors declare no conflict of interest.

\section{References}

1. Chang, T.-J.; Chen, C.-L.; Tu, Y.-L.; Yeh, H.-T.; Wu, Y.-T. Evaluation of the climate change impact on wind resources in Taiwan Strait. Energy Convers. Manag. 2015, 95, 435-445. [CrossRef]

2. Pryor, S.; Barthelmie, R. Hybrid downscaling of wind climates over the eastern USA. Environ. Res. Lett. 2014, 9, 024013. [CrossRef] 
3. Alizadeh, M.J.; Kavianpour, M.R.; Kamranzad, B.; Etemad-Shahidi, A. A weibull distribution based technique for downscaling of climatic wind field. Asia Pac. J. Atmos. Sci. 2019, 55, 685-700. [CrossRef]

4. Heikkilä, U.; Sandvik, A.; Sorteberg, A. Dynamical downscaling of ERA-40 in complex terrain using the WRF regional climate model. Clim. Dyn. 2011, 37, 1551-1564. [CrossRef]

5. Soares, P.M.; Cardoso, R.M.; Miranda, P.M.; de Medeiros, J.; Belo-Pereira, M.; Espirito-Santo, F. WRF high resolution dynamical downscaling of ERA-Interim for Portugal. Clim. Dyn. 2012, 39, 2497-2522. [CrossRef]

6. Flaounas, E.; Drobinski, P.; Bastin, S. Dynamical downscaling of IPSL-CM5 CMIP5 historical simulations over the Mediterranean: Benefits on the representation of regional surface winds and cyclogenesis. Clim. Dyn. 2013, 40, 2497-2513. [CrossRef]

7. Horvath, K.; Koracin, D.; Vellore, R.; Jiang, J.; Belu, R. Sub-kilometer dynamical downscaling of near-surface winds in complex terrain using WRF and MM5 mesoscale models. J. Geophys. Res. Atmos. 2012, 117, 1-19. [CrossRef]

8. Tobin, I.; Jerez, S.; Vautard, R.; Thais, F.; Van Meijgaard, E.; Prein, A.; Déqué, M.; Kotlarski, S.; Maule, C.F.; Nikulin, G.; et al. Climate change impacts on the power generation potential of a European mid-century wind farms scenario. Environ. Res. Lett. 2016, 11, 034013. [CrossRef]

9. Cardoso, R.M.; Soares, P.M.; Lima, D.C.; Semedo, A. The impact of climate change on the Iberian low-level wind jet: EURO-CORDEX regional climate simulation. Tellus A: Dyn. Meteorol. Oceanogr. 2016, 68, 29005. [CrossRef]

10. Laprise, R.; Hernández-Díaz, L.; Tete, K.; Sushama, L.; Šeparović, L.; Martynov, A.; Winger, K.; Valin, M. Climate projections over CORDEX Africa domain using the fifth-generation Canadian Regional Climate Model (CRCM5). Clim. Dyn. 2013, 41, 3219-3246. [CrossRef]

11. Pattnayak, K.; Panda, S.; Saraswat, V.; Dash, S. Assessment of two versions of regional climate model in simulating the Indian Summer Monsoon over South Asia CORDEX domain. Clim. Dyn. 2018, 50, 3049-3061. [CrossRef]

12. Manyeredzi, T.; Makaka, G. An assessment of the wind power generation potential of Built Environment Wind Turbine (BEWT) systems in fort beaufort, South Africa. Sustainability 2018, 10, 1346. [CrossRef]

13. Amirinia, G.; Kamranzad, B.; Mafi, S. Wind and wave energy potential in southern Caspian Sea using uncertainty analysis. Energy 2017, 120, 332-345. [CrossRef]

14. Warnock, J.; McMillan, D.; Pilgrim, J.; Shenton, S. Failure rates of offshore wind transmission systems. Energies 2019, 12, 2682. [CrossRef]

15. Ulazia, A.; Nafarrate, A.; Ibarra-Berastegi, G.; Sáenz, J.; Carreno-Madinabeitia, S. The consequences of air density variations over Northeastern Scotland for offshore wind energy potential. Energies 2019, 12, 2635. [CrossRef]

16. Kucuksari, S.; Erdogan, N.; Cali, U. Impact of electrical topology, capacity factor and line length on economic performance of offshore wind investments. Energies 2019, 12, 3191. [CrossRef]

17. Florescu, A.; Barabas, S.; Dobrescu, T. Research on increasing the performance of wind power plants for sustainable development. Sustainability 2019, 11, 1266. [CrossRef]

18. Chang, T.-J.; Wu, Y.-T.; Hsu, H.-Y.; Chu, C.-R.; Liao, C.-M. Assessment of wind characteristics and wind turbine characteristics in Taiwan. Renew. Energy 2003, 28, 851-871. [CrossRef]

19. Rezk, H.; Fathy, A.; Diab, A.A.Z.; Al-Dhaifallah, M. The application of water cycle optimization algorithm for optimal placement of wind turbines in wind farms. Energies 2019, 12, 4335. [CrossRef]

20. Yang, K.; Cho, K. Simulated annealing algorithm for wind farm layout optimization: A benchmark study. Energies 2019, 12, 4403. [CrossRef]

21. Davy, R.; Gnatiuk, N.; Pettersson, L.; Bobylev, L. Climate change impacts on wind energy potential in the European domain with a focus on the Black Sea. Renew. Sustain. Energy Rev. 2018, 81, 1652-1659. [CrossRef]

22. Rasmussen, D.; Holloway, T.; Nemet, G. Opportunities and challenges in assessing climate change impacts on wind energy-A critical comparison of wind speed projections in California. Environ. Res. Lett. 2011, 6, 024008.

23. Yao, Y.; Huang, G.H.; Lin, Q. Climate change impacts on Ontario wind power resource. Environ. Syst. Res. 2012, 1, 2.

24. Kamranzad, B. Persian Gulf zone classification based on the wind and wave climate variability. Ocean Eng. 2018, 169, 604-635. [CrossRef] 
25. Ulazia, A.; Ibarra-Berastegi, G.; Sáenz, J.; Carreno-Madinabeitia, S.; González-Rojí, S.J. Seasonal correction of offshore wind energy potential due to air density: Case of the Iberian Peninsula. Sustainability 2019, 11, 3648. [CrossRef]

26. Taylor, P.K.; Yelland, M.J. On the apparent "imbalance" term in the turbulent kinetic energy budget. J. Atmos. Ocean. Technol. 2000, 17, 82-89. [CrossRef]

27. Amirinia, G.; Mafi, S.; Mazaheri, S. Offshore wind resource assessment of Persian Gulf using uncertainty analysis and GIS. Renew. Energy 2017, 113, 915-929. [CrossRef]

28. Porté-Agel, F.; Wu, Y.-T.; Chen, C.-H. A numerical study of the effects of wind direction on turbine wakes and power losses in a large wind farm. Energies 2013, 6, 5297-5313. [CrossRef]

29. Schindler, D.; Jung, C. Copula-based estimation of directional wind energy yield: A case study from Germany. Energy Convers. Manag. 2018, 169, 359-370. [CrossRef]

(C) 2020 by the authors. Licensee MDPI, Basel, Switzerland. This article is an open access article distributed under the terms and conditions of the Creative Commons Attribution (CC BY) license (http://creativecommons.org/licenses/by/4.0/). 